\title{
Applying an ecosystem services approach to support land-use planning: a case study in Koboko district, Uganda
}

\author{
Lighea Speziale ${ }^{1}$ and Davide Geneletti ${ }^{1,2^{*}}$
}

\begin{abstract}
Introduction: This paper presents a case study of the application of an ecosystem services framework to support land-use planning. The district of Koboko, in northwestern Uganda, formed the study area. The overall purpose was to improve the understanding of links between human actions, their impact on ecosystems and the services they provide, and, ultimately, consequences for human wellbeing. The framework developed by the Millennium Ecosystem Assessment was used as a main conceptual reference.

The analysis comprised four main stages: (1) identification of the main ecosystems and their services; (2) analysis of human wellbeing components, focusing on poverty issues; (3) assessment of the interrelations between ecosystem services and human wellbeing; (4) identification of the main drivers of change and development of future spatial development scenarios.

Results: The scenarios were developed starting from the main drivers of change and show the dependency of human wellbeing on ecosystems services, identifying how spatial development strategies can affect that dependency. Quantitative information was not easily available, therefore scenario development made use of both quantitative and qualitative analysis. The results of qualitative and quantitative approaches were consistent, proving the strength and flexibility of the method.

Conclusions: Scenario results aim to provide guidance for local government land-use planning, focusing on the promotion of sustainability through ecosystem services preservation. The spatially explicit analysis illustrated how different policies affect urban development; it was clearly shown that even with very different demographic outcomes, the impact of sectorial policies guaranteed a good level of suitability for new residential areas.
\end{abstract}

\section{Introduction}

The importance of ecosystem services for human wellbeing is well established. In the last ten years there has been a significant increase in scientific papers focusing on ecosystem services (Fisher et al. 2009), fuelled by the Millennium Ecosystem Assessment, which pointed out the many interrelations between nature and society. Thanks to the Millennium Ecosystem Assessment, many studies were carried out to explore these issues in more detail, with the overall aim of promoting sustainable development. However, how the analysis on ecosystems

\footnotetext{
*Correspondence: davide.geneletti@unitn.it

'Department of Civil, Environmental and Mechanical Engineering, University of Trento, Via Mesiano 77, 38123 Trento, Italy

${ }^{2}$ UNESCO Chair in Engineering for Human and Sustainable Development, University of Trento, Via Mesiano 77, 38123 Trento, Italy
}

and human wellbeing can be directly used for land-use planning purposes has not been developed to the same extent (Daily et al. 2009). A comprehensive approach that includes impacts on ecosystem services would be a significant improvement for promoting sustainability in spatial planning decisions. This is especially true considering that sectorial policies and strategies should be well integrated within a spatial plan and that an ecosystem approach provides the comprehensive framework needed to reach this objective.

This paper presents a case study related to the application of an ecosystem services approach to supporting land-use planning. The study aimed at improving the understanding of the links between human actions, the impacts on the state of ecosystems and the services they provide, and ultimately the consequences

\section{实}


for human wellbeing. The case study area is the district of Koboko, a poor yet fast-developing region in Uganda.

\section{Study context}

Koboko district (located in the northwestern corner of Uganda, see Figure 1) is named after its chief town, Koboko, where the district headquarters are located. The district covers a surface of about $770 \mathrm{~km}^{2}$ and has a population of roughly 200,000 people (2010 estimation; Uganda Bureau of Statistics, 2010). It is one of the poorest districts in Northern Uganda and is characterized by the highest rates of rural poverty (Emwanu et al. 2003). Livelihood systems are based mainly on agriculture (which provides nutrition for about $90 \%$ of the population; Arua 2004) and livestock.

The district has a mixture of ethnic groups, with inhabitants also coming from neighbouring countries, such as the Democratic Republic of Congo, Southern Sudan and even Somalia. Furthermore, a massive number of refugees, who settled in 1995 in the northeastern area of the district, caused an extreme acceleration in the depletion of the ecosystems, especially in forest areas (United Nations Environment Programme, 2007). Annual population growth rate has been estimated at $5.6 \%$, which is higher than the national average (Uganda Bureau of Statistics, 2010). Fertility rates in Koboko are among the highest in the country (the average number of children per woman is 7, according to UBS 2010).

Key environmental concerns for the district include (National Environmental Management Authority, 2006;

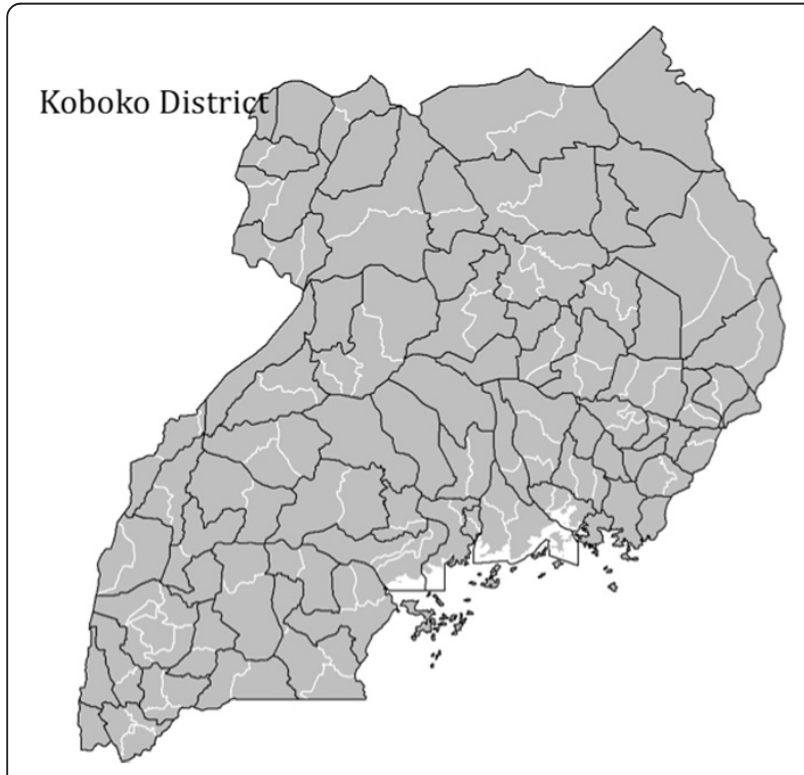

Figure 1 Location of Koboko district, Uganda.
Uganda Bureau of Statistics, 2002; Rogers et al. 2006; Kibreab, 1997; Byakola and Mukheibr, 2009):

- Poor health and sanitation,

- Deforestation,

- Poor waste management,

- Wetland and river bank degradation,

- Environmental pollution,

- Overgrazing,

- Poor land management,

- Conflict with protected area management.

Over the last 15 years, land use has changed significantly, owing to deforestation processes and growth of the urban area. In addition, croplands have expanded into areas previously covered by forests. The nearly complete conversion of wetlands, forests and savannah woodlands into agricultural farms has negatively affected the supply of provisioning ecosystem services, such as water and firewood.

The town of Koboko has become a very important player in the district dynamics, particularly because the current population is 51,300 people. The average household size is 7.3 members and the average household density has been calculated as about 211 people per hectare. The high population is also due to the immigration of refugees and returnees from Sudan and neighbouring districts (Ministry of Local Government, 2007). Districtscale dynamics have proven to be deeply connected to urban processes, especially because urban features are still very close to rural lifestyles. Consistently with district trends, agriculture is also a major activity in the town. The most common crops are tobacco and cassava; their production is concentrated in the villages, away from the town centre (Ministry of Local Government, 2007).

\section{Methods}

The work developed for the Millennium Ecosystem Assessment was taken as an inspiration for the study: the interrelations between ecosystem services and human wellbeing were analyzed and spatial development scenarios were obtained, thanks to the drivers of change identified. The purpose was to point out the closed link between human wellbeing and ecosystem services, in order to provide guidelines for policymakers.

Building on Ash et al. (2010), the method is based on four main stages:

1. Assessment of the interrelations between ecosystem services and human wellbeing;

2. Identification and evaluation of the main drivers of change; 
3. Development of future spatial scenarios, combining of qualitative and quantitative information;

4. Comparison of scenarios through social and environmental indicators.

\section{Assessment of the interrelations between ecosystem services and human wellbeing}

The links between ecosystems and human wellbeing were identified following the framework proposed by the Millennium Ecosystem Assessment. The main ecosystems were identified with a land-use map of the study area generated by satellite image processing. The image analyzed was a Landsat frame from 2005 (the most recent available) with a pixel resolution of $60 \mathrm{~m}$. Image processing was performed using supervised classification, with GRASS GIS software. The result of the classification was then compared with data collected by field surveys using a global positioning satellite. The following land-use types were classified: woodland, degraded woodland, grassland, farmland and urban areas (Speziale, 2012).

Socio-economic information about human wellbeing and poverty levels was collected by reviewing available reports and other literature (Uganda Bureau of Statistics, 2010; International Institute for Sustainable Development, 2005; Bahiigwa and Muramira, 2001; Emwanu et al. 2003; Robinson and Pozzi, 2011; Rogers et al. 2006), as well as by field surveys. A total of 100 households were sampled randomly throughout the four wards of the town of Koboko and data on housing equipment, water and sanitation, and demographics were collected. The collection was carried out together with the town council staff in order to facilitate communication and clarify doubts about the questions asked. The main vulnerability factors were represented by food security, limited livelihood opportunities and firewood shortage. Other critical factors, particularly considering the high rate of population growth, were poor farming methods, land fragmentation and degradation of forest land (International Institute for Sustainable Development, 2005; National Environmental Management Authority, 2006).

\section{Identification and evaluation of the main drivers of change}

Once the socio-ecological system was studied, it was possible to select the main drivers of change using expert opinions, a literature review (Uganda Bureau of Statistics, 2010; United Nations Environment Programme, 2007; Arua DLG, 2004) and field work. The main indirect drivers considered are demographic change and economic change, whereas direct drivers are land-use change, climate change and overexploitation of natural resources. To develop a solid basis for the elaboration of future scenarios, the selected drivers of change were analyzed on a quantitative and/or a qualitative level (depending on the specific driver). For example, landuse change was analysed using GIS software, based on supervised classification of Landsat images (from 1995 and 2005). Demographic trend was projected by analyzing the census data available for the last 20 years.

The evaluation of the main drivers of change was used to classify their degree of impact on ecosystems and human wellbeing and their current trend, in order to identify main concerns for future development. Consistent with the findings of Ash et al. (2010), the impact of each driver on the ecosystems included in the analysis and the components of human wellbeing was assessed using a low-medium-high scale, while the trend was described as decreasing, continuing, increasing or rapidly increasing.

\section{Development of future spatial scenarios}

Scenarios were developed starting from the main drivers of change and showing the dependency of human wellbeing on ecosystems services in order to identify how spatial development strategies can have an effect on that dependency. Following the method described in Ash et al. (2010), within the main scenarios developed, a quali-quantitative approach was adopted: the qualitative assessment was carried out at the district scale, while quantitative information was applied at the urban scale. This combination also helped in checking the consistency of qualitative outcomes against quantitative ones in the same scenario.

The process was defined through a deductive approach (Ash et al. 2010), starting with a discussion of the main uncertainties, driving forces, factors and actors that are expected to shape future trends and their interactions, and thus identifying the underlying scenario logics. The development of the scenario logics started with an analysis of the drivers of change: this analysis aimed at identifying the main drivers that play a role in the future and the possible trends and trajectories that a single driver can undertake. Moreover, the uncertainty regarding how these trends will play out in the future was a key aspect that helped to choose the most significant scenarios. Drivers were classified according to both the level of impact on the future outlook and the level of uncertainty, considered as the level of variation in the range of possible evolutions of the driver itself and the relative uncertainty (Jaeger et al. 2007). Therefore, it was possible to find the so-called critical uncertainties (Jaeger et al. 2007), which are especially important drivers for calculating how the future might evolve, but whose development is highly unpredictable. To be systematic in the selection process, an impact vs uncertainty matrix was used at first to score the drivers (see Figure 2). The intention was to locate the driver in terms of level of impact and the degree of uncertainty related to the driver's future path. After the first classification, a more specific classification was carried 


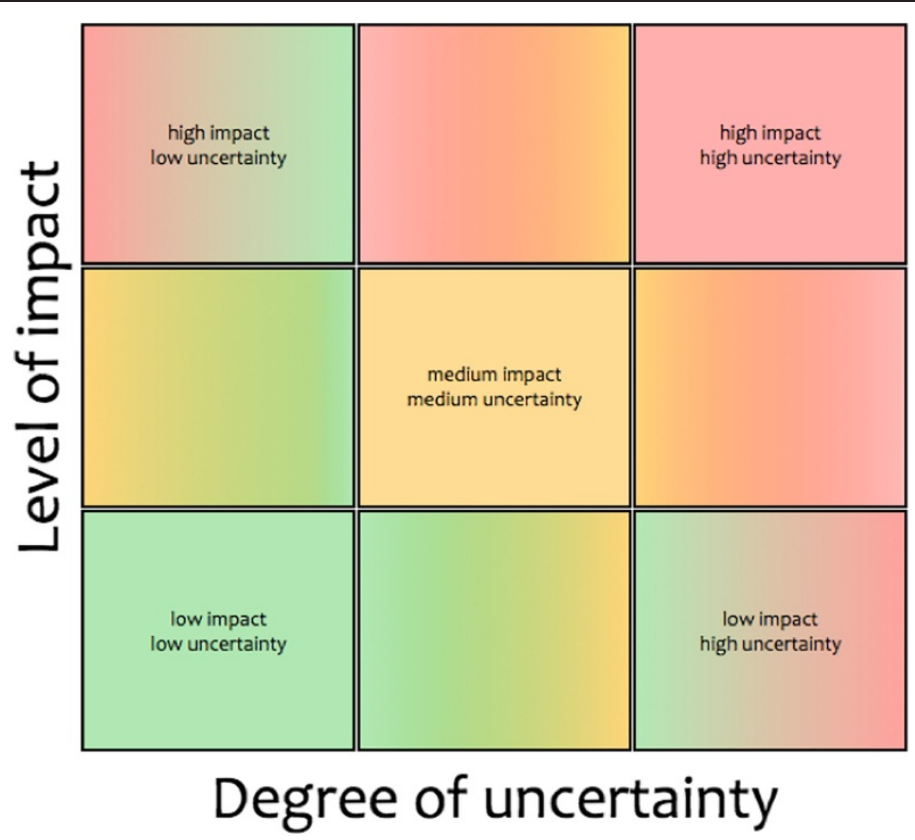

Figure 2 Impact vs uncertainty matrix used for the scenario logics.

out, to identify different degrees of impact/uncertainty inside the low, medium and high areas.

Among the drivers taken into account for this analysis, particular attention was paid to policies, because in spatial planning they have a significant influence. In particular they have been divided in spatial policies, meaning all the actions that can lead to a spatial development, and sectorial policies, or the political choices that can help finding substitutes for ecosystems services. For each driver identified as a critical uncertainty, the possible outcomes were unfolded and scenarios were obtained by combining the drivers' outcomes. Once the scenario set was completed, the most significant were selected: scenarios with outcomes that conflicted or contradicted each other were removed, because they were considered less likely to happen than the others. Moreover, some led to similar futures, thus making it harder to appreciate the different impacts: in this case, one scenario was chosen for analysis and considered representative of the others. Overall from the 24 possible combinations, four were chosen for further analysis and these were compared against each other using a series of indicators. The selected scenarios were named Far West, Eating Broth with a Fork, Full Steam Ahead and Atlantis. The following key quantitative indicators were selected to summarize the impacts of the different scenarios: deforestation rates, demographic trends and farmland demand.

The quantitative assessment proposed for the urban scale included assumptions on household density, making the work twofold: on one hand, the focus was on urban growth (with the assumption that all nonurban land is available for growth), while simultaneously suitability factors were identified, weighed and merged, to obtain suitability maps. To estimate urban expansion, the outcomes of demographic drivers of change considered for the qualitative analysis (without considering refugee flows) were taken into account, so that the resulting outcomes were consistent with the scenario analysis undertaken at a district scale. Furthermore, the impacts of an increase in household density were compared with those linked to scenarios where the density does not change.

The suitability model was based on critical factors that influence the likelihood of a certain area to be urbanized: these factors were implemented using GIS software, to perform a spatial multicriteria evaluation. In this case, the choice was based on literature data about which factors are more attractive in contexts such as the one studied (Geneletti, 2012; Mendoza et al. 2009):

- Distance from city centre,

- Distance from rivers and streams,

- Distance from roads,

- Distance from water points,

- Distance from woodlands,

- Household density.

A number of factors were not considered in this analysis, such as industrial land expansion, road and bridge construction projects, ownership and land tenure, succession (for example, commercial replacing residential land use), affordability, political and commercial factors and urban development in the proximity of the area. 
The basic assumption considered was that all nonurban land is available for expansion.

The suitability factors were standardized and then weighted, according to priorities consistent with the critical uncertainties' outcomes in the selected scenarios. Concerning the weighting phase, not only was it taken into considerations that factors do not have the same importance in one scenario, but also that the same factor might weigh differently in different scenarios. An example is the weight assigned to distance from the forest: when wood is supplied following an organized pattern, people do not have to gather their own firewood from woodlands, and therefore living close to woodlands is not an influencing parameter. The suitability maps thus obtained were then applied to urban expansion, combining the two aspects of the evaluation.

\section{Comparison of scenarios through social and environmental indicators}

To analyse impacts of the different district-scale scenarios, social and environmental indicators were chosen based on the assessment of ecosystems and human vulnerabilities in the study area and generally used in scenario evaluations (Alcamo and Henrichs 2008, Jaeger et al. 2007, National Environmental Management Authority, 2008). Scenarios were then classified based on their performance according to the single indicator, using 'traffic light' options: red represented a bad performance, green a good one and orange a medium one. Once scenarios were ranked, a quantitative evaluation of the most critical indicators was undertaken: the impacts on land demand for farming purposes and firewood and charcoal demand (Knöpfle, 2004) showed, for each scenario, whether the natural resources of the area were sufficient to support the population's needs.

From the urban-scale analysis, a series of maps showing, for each scenario, the demand for new urban area and the associated suitability was obtained. Hence, for each map, it was possible to extract suitability thresholds associated to each scenario considered and provide conclusions based on scenario assumptions.

\section{Results and discussion}

Interrelations between ecosystem services and human wellbeing and drivers of change

Figure 3 presents the land-use map for 1995 and 2005. An overview of the parameters taken into account and their interconnections is presented in Figure 4. Impacts of the main drivers on both ecosystems and human wellbeing are shown in Figure 5. Land-use change impacts mainly on forests and wetlands and hence on availability of basic materials for a good life and health, related to poor nourishment. Moreover, the increasing trends of the drivers of change (see Figure 5) make land-use change a key factor when it comes to understanding future developments in ecosystem wellbeing. Climate change occurs at a different speed and therefore its impacts have not yet affected the wellbeing of the population as much as landuse change or overexploitation. It is expected that these changes will be sweeping only in the long term. Considering that climate change is an external driver, it was not taken into consideration for scenario development.

Overexploitation and pollution were analyzed together, because they presented similar outcomes for human wellbeing: with reference to the constituents of wellbeing underlined in Ash et al. (2010), security is the most affected part (because it undermines resources access) together with basic materials for health and a good life and (because they put access to clean water and food productivity at risk). However, their behaviour differs: analysis of ecosystems reveals that pollution mainly affects fresh water, while overexploitation impacts mainly on agroecosystems. This difference could be explained by considering that human wellbeing is a complex concept where many factors act together and therefore repercussions of ecosystems degradation are not linear or easily predictable.

\section{Development of future spatial scenarios}

Policies were included as external factors for the development of scenarios, because they can greatly influence the internal drivers considered (land-use change, overexploitation and economic growth). The choice was supported by the local political conditions: Koboko district is a relatively young political entity (it was part of the Arua district until 2005) and its local authorities are willing to act and contribute to improve the wellbeing of the population. All the identified drivers were classified on the basis of impact on future outlook and on the level of uncertainty (see Figure 6): in the lower uncertainty sector, drivers that have a known dependency on other drivers have mainly been located. For this reason, their outcome is considered as less uncertain, once leading drivers have played out.

This is the case of land-use change, urbanization, pollution and economic growth: if considered as stand-alone parameters, these drivers have a remarkable impact on future outcomes, but their impact also depends highly on policies' directions. If governments do not improve their sustainable actions, some drivers will grow out of control and will therefore affect ecosystems and human wellbeing heavily. Proactive actions could be undertaken to promote the development of formal settlements and waste treatment facilities and to avoid overexploitation, so that the impacts of those drivers would be reduced.

As explained in the Methods section., to develop future scenarios, it was necessary to identify critical uncertainties; that is, drivers that have the biggest impacts on future 


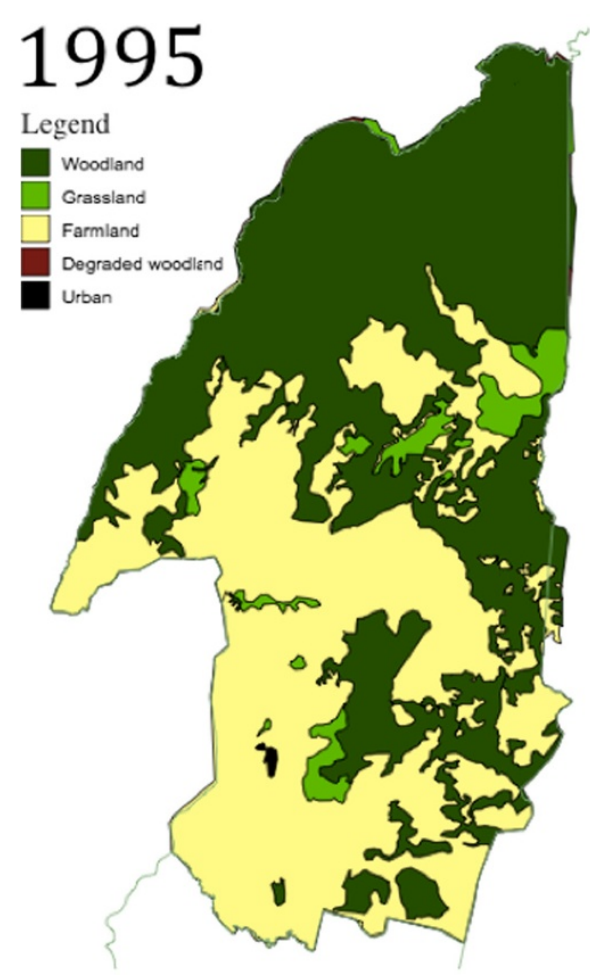

\section{5}

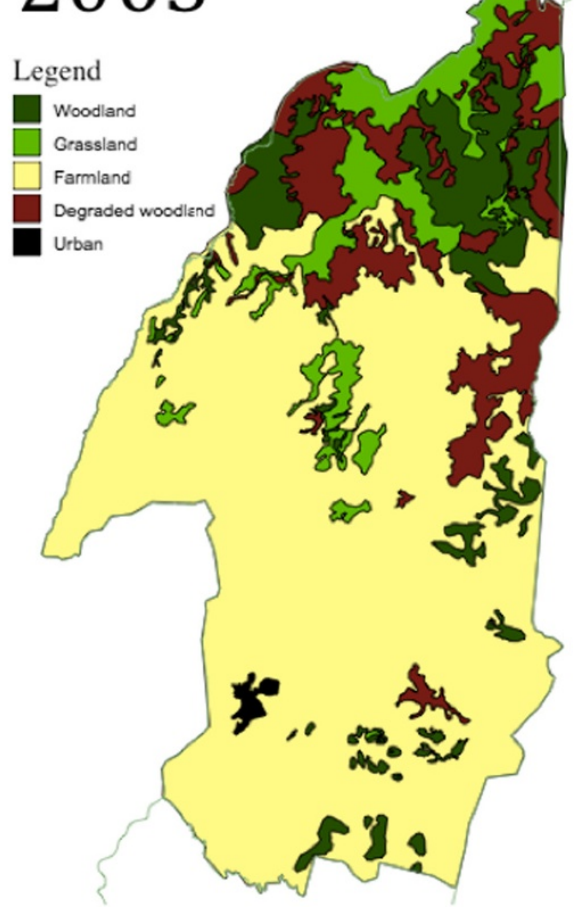

Figure 3 Land-use change in Koboko District in 1995 and 2005.

development and at the same time have highly unpredictable outcomes. The trend of migration and the sudden flow of refugees (Kanyamibwa, 2007), the sectorial policies adopted to meet ecosystem needs and empower them and the governance aiming at improving human wellbeing meet the requirements, as shown in Figure 6. Therefore, these three are the drivers taken into account to develop future scenarios, with the addition of the demographic trend, ${ }^{a}$ chosen because in fast-developing areas it greatly influences future outcomes despite its low uncertainty.

From the 24 scenarios obtained by mixing together the different outcomes of the critical uncertainties (see Table 1), only four were chosen for further analysis. Scenarios that presented conflicting outcomes of special policies and sectorial policies were removed: if the special policies move towards sustainability, sectorial policies will probably also be implemented (and vice versa). Moreover, some of the combinations led to similar futures, which made it difficult to appreciate the connections between the drivers' assumptions and resulting impacts, whether it be population increase with the most far-seeing special policies or the less sustainable policy with the slower demographic growth. Therefore, two scenarios were selected for further analysis: D3G2P1 (Full Steam Ahead) and D1G3P2 (Eating Broth with a Fork). The two scenarios remaining after the selection were the extreme ones: worst case, D1G1P1 (Far West), and best case, D4G3P2 (Atlantis).
As regards the quantitative assessment explained in the Methods section, urban expansion was evaluated by starting from the possible outcomes of the demographic drivers of change D3 and D4 (Table 1) in a time frame of 20 years and adding assumptions on household density (stable at 211 people per hectare or increasing up to 332 people per hectare, which is representative of the most densely populated areas of the town). Therefore, four outcomes for urban expansion were taken into account (see Table 2).

For the multicriteria analysis, however, suitability factors were standardized and then weighted according to the outcomes of special policies and sectorial policies considered for Far West (G1P1) and Atlantis (G3P2) (see Table 1). For this reason, two different standardization and weighting methods were carried out and the two suitability maps obtained were applied to the four urban expansion outcomes, thus providing six different scenarios. Nevertheless, following the same rationale as for district-scale scenarios, combinations between conflicting assumptions (for example, farsighted policies and uncontrolled increased in household density) were excluded from the analysis. Table 1 summarizes the analysis at the urban scale, showing the suitability threshold for each resulting scenario.

Maps showing the results of the analysis are presented in Figure 7. Scenarios A and B share the same urban 

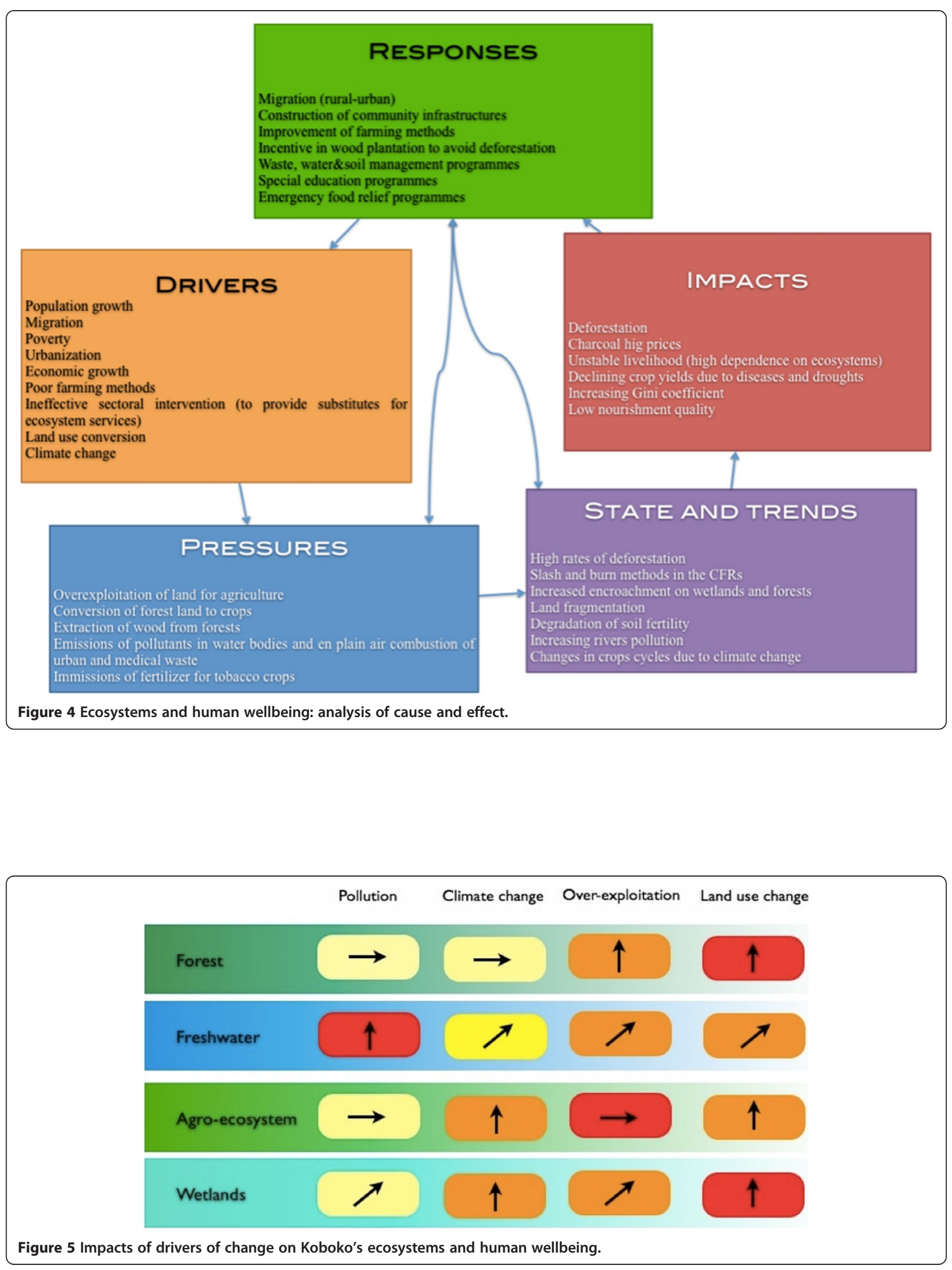


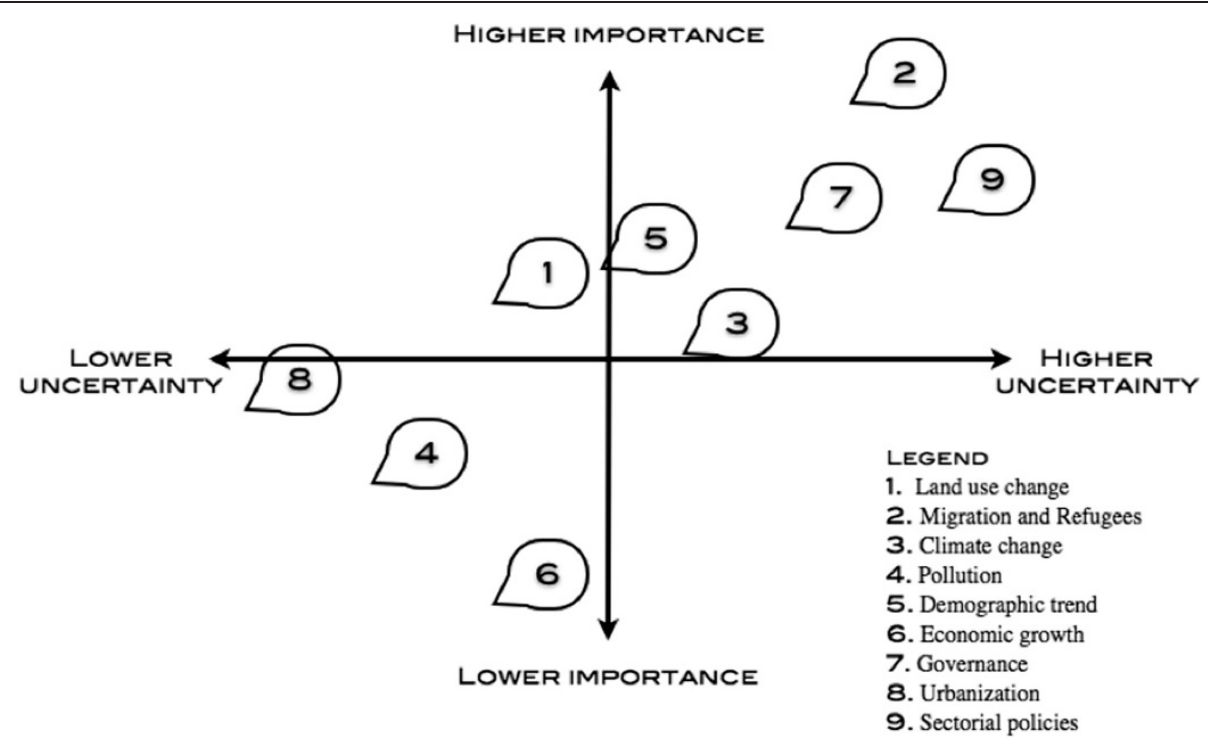

Figure 6 Classification of drivers based on level of importance and uncertainty.

expansion but with different suitability: in the first case new urban land will develop in a highly suitable area, unlike the second case, where informal urbanization will be relevant and therefore new urban land will not match suitability requirements. Similarly for C and D: suitability thresholds are higher than A and B because of lower population growth and therefore a lower demand for new urban areas. Comparing scenario $\mathrm{A}$ against $\mathrm{C}$ makes it possible to appreciate that when sustainable policies

Table 1 Outcomes of critical uncertainties selected for scenario development

\begin{tabular}{|c|c|c|}
\hline \multirow[t]{4}{*}{ Demography } & D1 & $\begin{array}{l}\text { Annual growth rate settles to } 3.4 \% \text { (national } \\
\text { value) and migration fluxes are relevant. }\end{array}$ \\
\hline & $\mathrm{D} 2$ & $\begin{array}{l}\text { Annual growth rate settles to } 2.6 \% \text { and } \\
\text { migration fluxes are relevant. }\end{array}$ \\
\hline & D3 & $\begin{array}{l}\text { Annual growth rate settles to } 3.4 \% \\
\text { (national value). }\end{array}$ \\
\hline & D4 & Annual growth rate settles to $2.6 \%$. \\
\hline \multirow[t]{6}{*}{ Special policies } & G1 & No spatial plan is developed. \\
\hline & & No specific infrastructures are built. \\
\hline & $\mathrm{G} 2$ & No spatial plan is developed. \\
\hline & & $\begin{array}{l}\text { Electricity is provided through the national grid } \\
\text { and the main road of Koboko town centre is } \\
\text { tarred. }\end{array}$ \\
\hline & G3 & Spatial plan is developed. \\
\hline & & $\begin{array}{l}\text { Electricity is provided through the national grid, } \\
\text { the main road of Koboko town centre is tarred } \\
\text { and waste treatment facilities are built. }\end{array}$ \\
\hline \multirow[t]{2}{*}{ Sectorial policies } & P1 & No special policies are developed. \\
\hline & $\mathrm{P} 2$ & $\begin{array}{l}\text { Sectorial policies are developed to provide } \\
\text { replacement for ecosystem services: wood } \\
\text { plantations and support for development } \\
\text { for better farming methods. }\end{array}$ \\
\hline
\end{tabular}

are in place, the impact of population growth can be contained. Overall observations can also be made: if the outlook focuses on agricultural loss, and therefore land availability for subsistence farming, the best scenarios are C, D and F, as shown in Figure 7. This contrasts with the best outcomes from a social point of view, which show how lower density usually means better human conditions: from this point of view, scenarios A, B, C and D would be the best.

Considering also that the highest suitability threshold belongs to scenario $C$ and that the same scenario matches the other requirements explained previously, it can be concluded that scenario $\mathrm{C}$ brings together the best conditions for human and environmental wellbeing.

\section{Comparison of scenarios through social and environmental indicators}

To analyse the impacts of the different district-scale scenarios, two sets of indicators were chosen: first, qualitative indicators that are used to provide a comprehensive assessment (see Figure 8); second, the indicators that were evaluated quantitatively. As expected Far West performed worst, while Atlantis showed the best results. For poverty incidence and the Gini coefficient, it was possible to see a different performance in the same

Table 2 Outcomes for urban expansion analysis

\begin{tabular}{lllll}
\hline $\mathbf{2 0 3 2}$ & D3 & & D4 & \\
\hline Urban population & 114,502 & & 89,672 & \\
\hline Residential areas (ha) & A & B & A & B \\
\hline Residential area increase (ha) & 300 & 102 & 182 & 27 \\
\hline
\end{tabular}



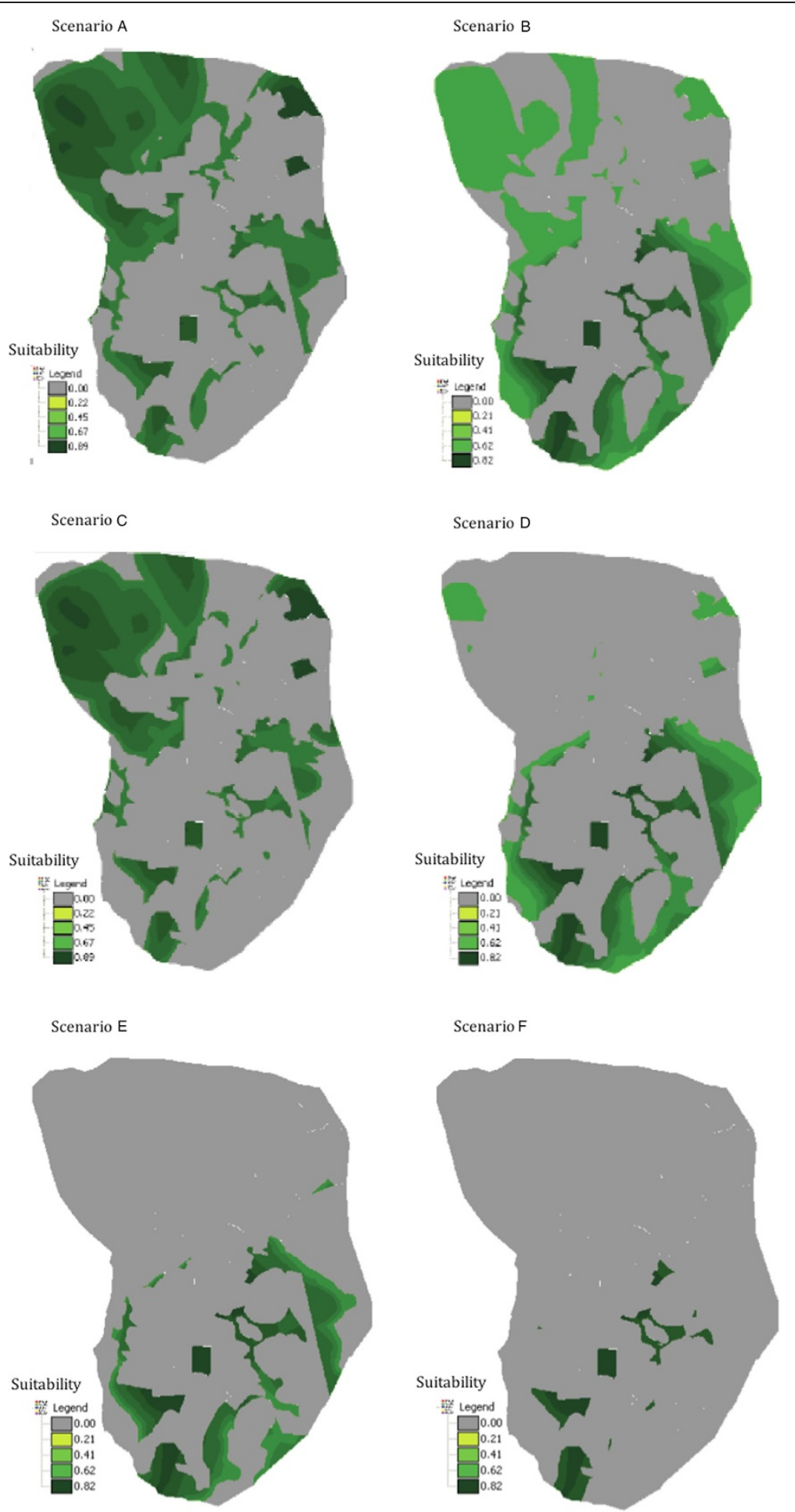

Figure $7 \mathrm{New}$ urban areas and their suitability values for the six quantitative scenarios. Suitability values are expressed in a 0-1 dimensionless scale, where zero represents the least suitable areas, and one the most suitable areas.

scenario: in Full Steam Ahead, for example, where economic growth played a major role, a small part of the population was expected to benefit from the process, while the rest would have very few resources to rely on.
Therefore, the poverty index was expected to decrease, while the Gini coefficient would increase, along with inequality. On the contrary, Far West implied a very high poverty incidence, because of the lack of resources due 


\begin{tabular}{lllll} 
& FAR WEST & $\begin{array}{c}\text { EATING BROTH } \\
\text { WITH THE FORK }\end{array}$ & FULL STEAM & ATLANTIS \\
\hline Waterborne diseases & & & & \\
\hline Malnourishment & & & & \\
\hline Food security & & & & \\
\hline Land tenure & & & & \\
\hline Poverty incidence & FATING BROTH & FULL STEAM & ATLANTIS \\
\hline Gini coefficient & & & & \\
\hline & & & & \\
\hline Water quality & & & & \\
\hline Loss of forest land & & & & \\
\hline Encroachment & & & & \\
\hline Loss of fertility & & & & \\
\hline Food productivity & & & & \\
\hline Soil erosion & & & & \\
\hline Non suitable cultivated areas & & & & \\
\hline Urban population density & & & & \\
\hline Safe water accessibility & & & & \\
\hline Cultivable land per hh & & & & \\
\hline New economic activities & & & & \\
\hline
\end{tabular}

Figure 8 Qualitative indicators for district-scale scenarios.

to massive human pressure on the environment, but the Gini coefficient was better than Full Steam Ahead because the conditions were expected to be very similar for every individual.

Overall, Full Steam Ahead improved the lifestyle of people involved in commercial and industrial activities, but for small farmers who practised subsistence agriculture there would be no positive impact. Atlantis empowers poor and marginalized groups, such as women, tends to increase equity regarding access to natural resources and, in general, improves human wellbeing.

The performance of Eating Broth with a Fork shows how farsighted policies can impact positively in the worst demographic picture. For a long-term perspective, where Atlantis is the scenario to aim at, Eating Broth with a Fork shows the effectiveness of human responses in the medium term. The indicators that do not perform very well are the ones heavily influenced by demography: change in population growth happens slowly and the effects of good governance appear only in the medium or long term.

The quantitative analysis was carried out consistently with the data available; therefore, for the district scale it is possible to estimate trends for population and the pressure on agro-ecosystem and forest. Figure 9 demonstrates how sectorial policies can influence heavily the impact on ecosystems: Eating Broth with a Fork has the highest population growth, but the demand for forest products is lower than Far West and Full Steam Ahead because it ensures that sectorial policies include enough

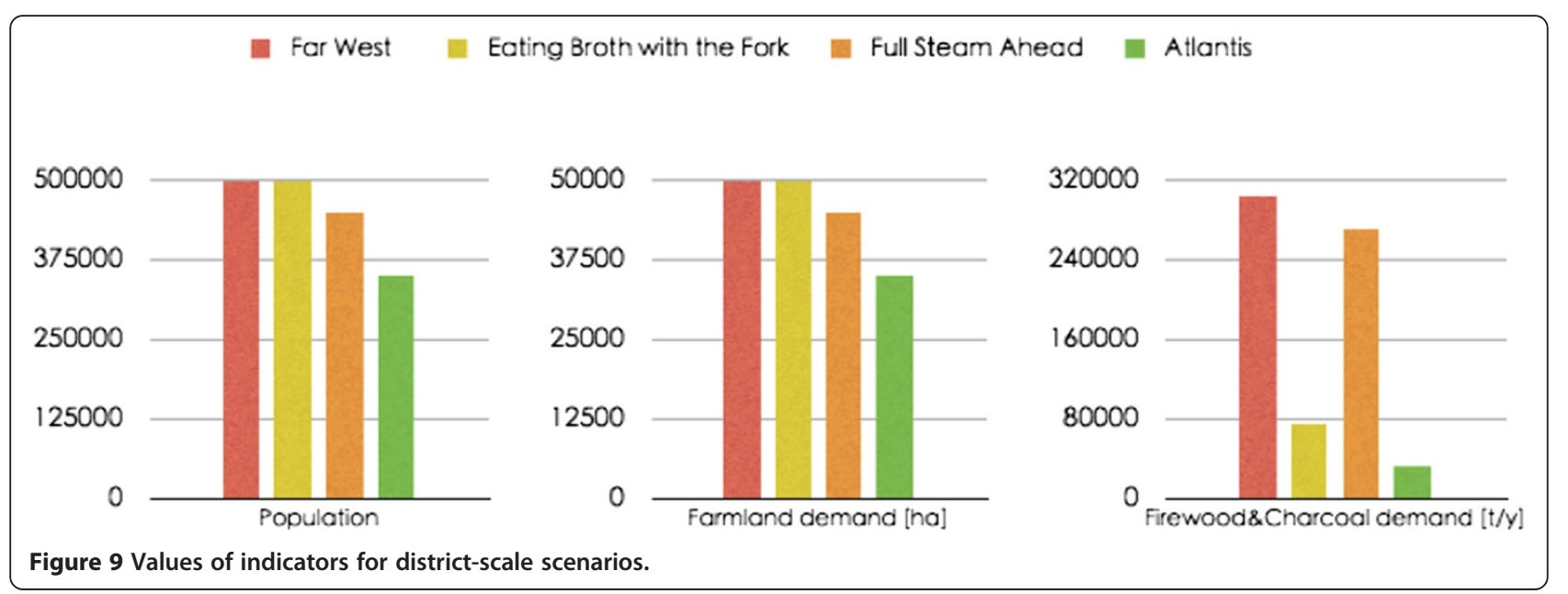




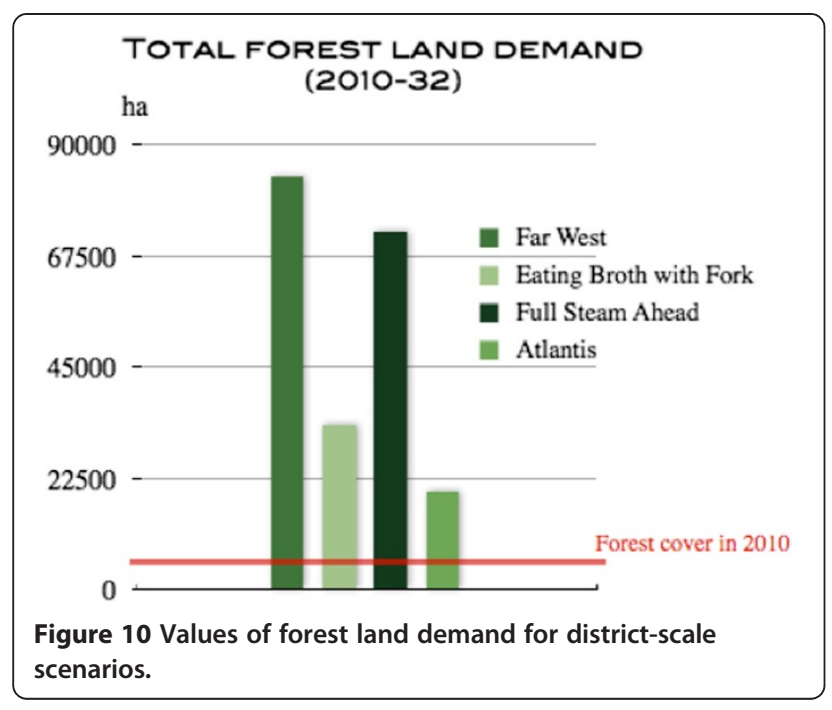

wood plantation to meet the rural demand for firewood and charcoal. This is also why firewood and charcoal demand in Atlantis is significantly lower than in the other scenarios. Regarding farmland demand, a value of 0.1 ha per person is assumed (Nonhebel, 2005) in every scenario, therefore the trend is consistent with population outcomes. Taking into account that the free arable land in the district in 2005 was about 52,400 ha and the demand increases to 49,800 ha in the worst case scenario, land conflicts for the most fertile areas in the future are likely to occur. The results for firewood and charcoal demand (see Figure 10) show clearly that the district resources are not sufficient for the population: depending on the scenario, if the whole demand of the district is to be satisfied by its forest land, complete deforestation will happen between 2015 and 2020. In fact, the 2010 demand of forest land is already one-third of the total forest cover; sectorial policies to avoid further deforestation are therefore an absolute priority.

Overall, the results at the urban scale were consistent with the performances of district scenarios. To compare the six results, suitability thresholds were calculated (see Table 3): these were used as a comprehensive indicator because they include all the parameters used to develop suitability maps. Moreover, the percentage of people settling in highly suitable areas can change the planners' approach when it comes to where and which services must be provided to the population.

In scenarios $A$ and $C$, suitability thresholds are the same (see Table 3): priorities are related to providing firewood and charcoal, so that the remaining woodland can be preserved, and controlling household density, so that it is still possible for people to own the land essential for survival. To guarantee charcoal for urban demand, it is recommended that wood plantations be implemented in the surroundings.
Table 3 Suitability thresholds for the six urban scenarios

\begin{tabular}{ll}
\hline Urban-scale scenario & Suitability threshold \\
\hline A (Atlantis in urban area with D3a) & 0.83 \\
\hline B (Far West in urban area with D3a) & 0.67 \\
\hline C (Atlantis in urban area with D4a) & 0.84 \\
\hline $\mathrm{D}$ (Far West in urban area with D4a) & 0.71 \\
\hline E (Far West in urban area with D3b) & 0.76 \\
\hline F (Far West in urban area with D4b) & 0.80 \\
\hline
\end{tabular}

Suitability values are expressed in a 0-1 dimensionless scale, where zero represents the least suitable areas, and one the most suitable areas.

In no-policies scenarios, such as B and D, people will tend to live close to rivers, roads and forests; in these places, population density will increase rapidly. It would be important that policies at least control and protect the forest reserve and avoid encroachments.

A quite risky strategy would be to let the household density increase: as shown in Figure 7, this would be a good outcome for land-use conversion, because less land is required for the same population, but concentrating the inhabitants in a small area can lead to several social problems. Moreover, people would still need to cultivate for subsistence, which would force them to cover a long distance every day.

\section{Conclusions}

This paper presented a method to support spatial planning and decision making when they aim at improving the sustainability of the relation between human wellbeing and ecosystem services. The method was consistent with the principles expressed in the Millennium Ecosystem Assessment and addressed the growing need to include ecosystem-based approaches in decision making and land-use planning (Daily and Matson 2008, Carpenter et al. 2009, Fisher et al. 2009, Hauck et al. 2013).

The proposed method allows decision makers to see the consequences of environmental and sectorial policies and to understand how human actions are connected to the state of ecosystem services. Furthermore, it enables identification of the critical issues of the study area, to focus on the aspects that provide the biggest impacts on ecosystems and to identify additional studies needed to improve the analysis of the context.

Many studies were carried out to assess the interrelations between ecosystem services and human wellbeing, but less attention has been paid to the provision of information that can be directly used for land-use planning. This method provided a comprehensive approach,- from the analysis of the ecosystem services to the comparison of scenarios, to fulfil this aim and was applied to a case study in order to show how the analysis can provide 
guidance for land-use planning. Moreover, the analysis was designed to be flexible, given the study context: lack of data (especially statistical data and adequate satellite images) and tools was overcome through flexibility of the method and the comparison of qualitative and quantitative assessment to ensure that the robustness of the results compensated for the incomplete set of information available. The general approach followed can be replicated in contexts similar to Koboko district: rural areas of Uganda, and sub-Saharan Africa in general, that are characterized by poverty and strong dependence of the population on ecosystem services are good candidates for testing the method, adapting assumptions to specific environmental and social conditions.

The identification of the critical uncertainties was one of the most important steps in connecting the analysis of the linkages between human wellbeing and ecosystem services to the development of scenarios dedicated to land-use planning purposes. The choice of these uncertainties was based on literature, but also on the results of the framework assessing the interrelations between the human and the ecosystem spheres in the study area. To guarantee clear messages for decision makers, the number of key uncertainties was low: this allowed to show straightforward cause-and-effect chains and to point out the environmental effect of the different policies applied (Geneletti, 2012).

Moreover, the comparison between qualitative scenarios, at the district scale, and quantitative scenarios, at the urban scale, fully supported the belief that selected aspects of qualitative scenarios may be underpinned by numerical estimates and that the numerical estimates of a quantitative scenario may be bound together and explained using a consistent storyline. Notwithstanding the different scales between qualitative and quantitative analysis, the results have shown deep consistency, ensuring the quality of the scenarios developed.

The spatially explicit analysis demonstrated how different policies will affect urban development: it was clearly shown by the results of this method how even with very different demographic outcomes, the impact of sectorial policies guaranteed a good level of suitability for the new residential areas.

\section{Endnote}

${ }^{\mathrm{a}}$ In D2 and D4, the annual growth rate foreseen is $2.6 \%$. This value is consistent with the rate in Kenya and Tanzania, the other two countries in the East African Community that have the same trends in Human Development Index as Uganda (United Nations Development Programme, 2012).

\section{Competing interests}

The authors declare that they have no competing interest.

\section{Authors' contributions}

LS conducted the field work and carried out the analysis. Both authors conceived the study, participated in its design, and worked together to draft the manuscript. Both authors read and approved the final manuscript.

\section{Acknowledgements}

The authors would like to thank ACAV - Associazione Centro Aiuti Volontari for the hospitality and the support provided during field work.

Received: 23 December 2013 Accepted: 16 March 2014

Published: 4 May 2014

\section{References}

Alcamo J, Henrichs T (2008) Towards guidelines for environmental scenario analysis. In: Alcamo J (ed) Environmental futures: the practice of environmental scenario analysis. Elsevier, Amsterdam

Arua DLG (2004) District state of environment report. Arua, Uganda

Ash N, Blanco H, Brown C, Garcia K, Henrichs T, Lucas N, Raudsepp-Hearne C, Simpson RD, Scholes R, Tomich TP, Vira B, Zurek M (2010) Ecosystems and human well-being: a manual for assessment practitioners. Island Press, Washington

Bahiigwa G, Muramira TE (2001) Poverty relevant environmental indicators for Uganda, Economic Policy Research Centre, Makerere, Kampala, Uganda and National Environment Management Authority, Kampala, Uganda

Byakola T, Mukheibr P (2009) Energy systems: vulnerability, adaptation, resilience. Helio International, Focus, Uganda

Carpenter SR, Mooney HA, Agard J, Capistrano D, DeFries RS, Díaz S, Dietz T, Duraiappah AK, Oteng-Yeboah A, Pereira HM, Perrings C, Reid W, Sarukhan J, Scholes RJ, Whyte A (2009) Science for managing ecosystem services: beyond the Millennium Ecosystem Assessment. Proc Natl Acad Sci U S A 106(5):1305-1312

Daily GC, Matson PA (2008) Ecosystem services: from theory to implementation. Proc Natl Acad Sci U S A 105(28):9455-9456

Daily GC, Polasky S, Goldstein J, Kareiva PM, Mooney HA, Pejchar L, Rickets TH Salzman J, Shallenberger R (2009) Ecosystem services in decision making: time to deliver. Front Ecol Environ 7(1):21-28

Emwanu T, Okwi PO, Hoogeween JG, Kristjanson P (2003) Where are the poor? Mapping patterns of well-being in Uganda. Uganda Bureau of Statistics, Kampala

Fisher B, Kerry TR, Morling P (2009) Defining and classifying ecosystem services for decision making. Ecol Econ 68:643-653

Geneletti D (2012) Environmental assessment of spatial plan policies through land use scenarios. Environ Impact Assess Rev 32(1):1-10

Hauck J, Schweppe-Kraft B, Albert C, Görg C, Jax K, Jensen R, Fürst C, Maes J, Ring I, Hönigovà I, Burkhard B, Mehring M, Tiefenbach M, Grunewald K, Schwarzer M, Meurer J, Sommerhäuser M, Priess JA, Schmidt J, Grêt-Regamey A (2013) The promise of the ecosystem services concept for planning and decisionmaking. GAiA - Ecol Perspect Sci Soc 22(4):217-288

International Institute for Sustainable Development (2005) Connecting poverty and ecosystem services: focus on Uganda. United Nations Environment Programme, Nairobi, Kenya

Jaeger JD, Rothman C, Anastasi S, Katha Van Notten P (2007) Training Module 6 : Scenario Development and analysis. In: GEO resource book: A training manual on integrated environmental assessment and reporting. UN Environment Programme and International Institute for Sustainable Development, Nairobi

Kanyamibwa S (2007) Great Lake Region. In: Impact of refugees and internally displaced persons on ecosystem integrity, Sudan post-conflict environmental assessment. Albertine Rift Conservation Society, Kampala

Kibreab G (1997) Environmental causes and impacts of refugee movements: a critique of the current debate. Disasters 21(1):20-38

Knöpfle M (2004) A study on charcoal supply in Kampala: final report. Ministry of Energy and Mineral Development (MEMD), Energy Advisory Project (EAP), Kampala

Mendoza M, López E, Morales-Manilla LM, Alcántara C, Geneletti D, Bocco G (2009) Land suitability analysis to support environmental planning: a multicriteria study in Morelia, Mexico. In: Geneletti D, Alias A (eds) Spatial decision support for urban and environmental planning, A collection of case studies. Arah Publications, Kuala Lumpur

Ministry of Local Government (2007) Koboko town council structure plan, final report. Ministry of Local Government, Koboko, Uganda 
National Environmental Management Authority (2006) Ecosystems, ecosystem services and their linkage to poverty reduction in Uganda. Centre for Resource Analysis, Ltd, Kampala

National Environmental Management Authority (2008) Pilot integrated environment assessment of the Lake Kyoga catchment area. National Environment Management Authority (NEMA), Kampala

Nonhebel S (2005) Renewable energy and food supply: will there be enough land? Renew Sust Energ Rev 9(2):191-201

Robinson T, Pozzi F (2011) Wealth index mapping in the horn of Africa: Animal Production and Health Working Paper. Food and Agriculture Organization, Rome

Rogers D, Emwanu T, Robinson T (2006) Poverty mapping in Uganda: an analysis using remotely sensed and other environmental data, pro-poor livestock policy initiative. Food and Agriculture Organization, Rome

Speziale L (2012) Applying the ecosystem approach to land use planning in Koboko district. Master's thesis. University of Trento, Italy

Uganda Bureau of Statistics (2002) Uganda population and housing census, main report. Government of Uganda, Kampala

Uganda Bureau of Statistics (2010) Uganda population and housing census, main report. Government of Uganda, Kampala

United Nations Development Programme (2012) 2012 Human Development Report, Main Report. United Nations Development Programme, New York

United Nations Environment Programme (2007) Population displacement and the environment. In: Sudan post-conflict environmental assessment. United Nations Environment Programme, Nairobi, Kenya

doi:10.1186/2192-1709-3-10

Cite this article as: Speziale and Geneletti: Applying an ecosystem

services approach to support land-use planning: a case study in Koboko district, Uganda. Ecological Processes 2014 3:10.

\section{Submit your manuscript to a SpringerOpen ${ }^{\circ}$ journal and benefit from:}

- Convenient online submission

- Rigorous peer review

- Immediate publication on acceptance

- Open access: articles freely available online

- High visibility within the field

- Retaining the copyright to your article

Submit your next manuscript at $>$ springeropen.com 